
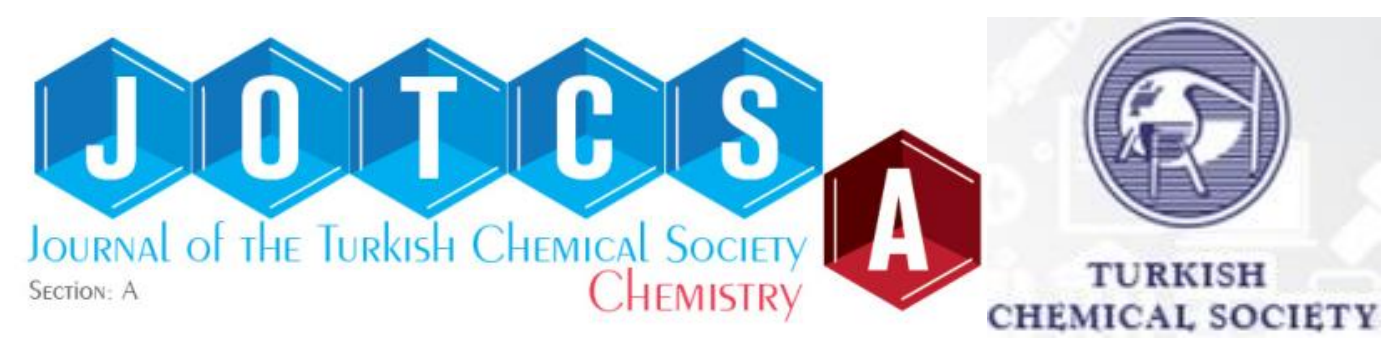

\title{
An Effective Method to Synthesize 2,3-Dihydroquinazolin-4(1H)- One Using Phosphate Fertilizers (MAP, DAP and TSP) as Green Heterogeneous Catalysts
}

\author{
Youssef MERROUN, Soukaina CHEHAB, Touriya GHAILANE, Said BOUKHRIS, \\ Rachida GHAILANE, Nouzha HABBADI, Amina HASSIKOU, Brahim LAKHRISSI \\ and Abdelaziz SOUIZI*
}

Laboratory of Organic, Organometallic and Theoretical Chemistry, University of IbnTofail, Faculty of Science, B.P. 133, 14000 Kenitra, Morocco

\begin{abstract}
In this work, an efficient, easy, and green process has been developed for the synthesis of 2,3-dihydroquinazolin-4(1H)-one from a condensation reaction of anthranylamide with various aromatic aldehyde using of phosphate fertilizers, monoammonium phosphate (MAP), di-ammonium phosphate (DAP) and triple super phosphate (TSP) as heterogeneous catalysts. The reaction conditions were optimized taking into account of some parameters which control the reaction, namely the nature and the volume of the solvent and the mass of catalyst. The results show that the catalysts used herein are very interesting because they present a good catalytic activity and they are reusable for at least five cycles without any degradation of their activity.
\end{abstract}

Keywords: Heterogeneous catalysis, phosphate fertilizer, MAP, DAP, TSP.

Submitted: July 12, 2017. Accepted: January 12, 2018.

Cite this: MERROUN Y, CHEHAB S, GHAILANE T, BOUKHRIS S, GHAILANE R, HABBADI N, et al. An Effective Method to Synthesize 2,3-Dihydroquinazolin-4(1H)-One Using Phosphate Fertilizers (MAP, DAP and TSP) as Green Heterogeneous Catalysts. JOTCSA. 2018;5(1):303-16.

DOI: http://dx.doi.org/10.18596/jotcsa.363818.

*Corresponding author. E-mail: contact@medjchem.com. 


\section{INTRODUCTION}

Heterocyclic chemistry forms an important branch of organic chemistry because it comprises at least half of all organic chemistry research worldwide. In particular, heterocyclic structures form the basis of many pharmaceutical, agrochemical, and veterinary products. There are numerous biologically active molecules whose framework includes a six-member ring containing two nitrogen atoms fused to a phenyl ring. Most of these molecules are based on the skeleton the dihydroquinazolin- $4(1 \mathrm{H})$-one.

The dihydroquinazolin- $4(1 \mathrm{H})$-one derivatives are an interesting class that exhibits a wide range of pharmacological and biological activity such as antitumor (1), diuretic (2), antiinflammatory (3), antianxietic (4), antifibrillatory (5), anti-hypertensive (6), vasodilating agent (7), analgesic (8), antihistaminic (9), anticancer (10), anticonvulsant (11), and antileishmanial (12). There are several methods in the literature for the synthesis of dihydroquinazolin-4(1H)-one, among which condensation of anthranylamide with aldehyde or ketones and three-component condensation isatoic anhydride, aldehyde and amine with an assortment of catalysts such as p-toluenesulfonic acid ( $\mathrm{p}-\mathrm{TsOH})(13)$, acetic acid (14), silica-bonded S-sulfonic acid (15), $\mathrm{SnCl}_{2}$ (16), Amberlyst-15 (17), aluminum tris (dihydrogen phosphate) $\left(\mathrm{Al}\left(\mathrm{H}_{2} \mathrm{PO}_{4}\right)_{3}\right)(18), \mathrm{Al} / \mathrm{Al}_{2} \mathrm{O}_{3}$ nanoparticles (19), $\mathrm{LaCl}_{3} / \mathrm{nanoSiO}_{2}$ (20), $\mathrm{Fe}_{3} \mathrm{O}_{4}$-SA-PPCA (21), $\beta$-cyclodextrin- $\mathrm{SO}_{3} \mathrm{H}$ (22), nanocrystalline sulfated zirconia (23), PEG-400 (24) and ionic liquid-water (25). These methods have some disadvantages such as hard reaction conditions, low yields, and long reaction times, they also require tedious processing procedures, as well as the application of strongly acidic catalysts, nonrecyclable, toxic and expensive. In addition, they use the toxic solvents. Therefore, these processes lead to a great loss of energy, as well as they are harmful to the environment.

As a continuation of our efforts to develop green synthetic methods, this work presents an easy, efficient, and ecological procedure for 2,3-dihydroquinazolin-4(1H)-one reaction using fertilizer phosphate catalysts, mono-ammonium phosphate (MAP), di-ammonium phosphate (DAP) and triple super phosphate (TSP) (26-28)which are solid catalysts, cheap, easy to reuse, and environmentally friendly. In this study, the recyclability, solvent effect, the influence of the catalyst amount and reaction time effect on the 2,3-dihydroquinazolin$4(1 \mathrm{H})$-one synthesis were studied. The novelty of this method appears in the fact that the catalysts MAP, DAP, and TSP are available, cheap and natural, and their use in the organic synthesis contribute to economize the cost and the energy and thus to develop green chemistry. 


\section{MATERIALS AND METHODS}

All of the chemicals and reagents used in this work were purchased from Sigma Aldrich. For all reactions, the purity of the derivatives 2,3-dihydroquinazolin-4 $(1 \mathrm{H})$-one was monitored by thin layer chromatography (TLC) using aluminum layers coated with F254 silica gel (Merck) plates using ethyl acetate and hexane as eluent. The melting points were recorded on a hot Kofler and show a good agreement with previous works.

\section{General procedure for the synthesis of 2,3-dihydroquinazolin-4(1H)-one}

$1 \mathrm{mmol}$ of anthranylamide and $1 \mathrm{mmol}$ of aromatic aldehyde were dissolved in $1 \mathrm{~mL}$ of $\mathrm{EtOH}$ in the presence of the catalyst MAP, DAP or TSP (Scheme 1). The reaction mixture was heated at reflux. The reaction is monitored by thin-layer chromatography (TLC) using ( $n$-hexane/EtOAc, v/v). After the reaction completion, the product was purified by recrystallization from ethanol and the solid catalyst is readily removed by simple filtration. The catalyst may be reactivated later by washing with ethanol to remove the products that may be present on its surface and then dried before being reused. The products obtained were characterized on the basis of comparison of their melting points and their spectroscopic data with those of literature (29-31).

2-(4-Chlorophenyl)-2,3-dihydroquinazolin-4(1H)-one 3a: ${ }^{1} \mathrm{H}$ NMR(300 MHz, DMSO-d6, delta, ppm): $8.35(1 \mathrm{H}, \mathrm{s}, \mathrm{NHCO}), 7.63(1 \mathrm{H}, \mathrm{s}), 7.54-7.45(4 \mathrm{H}, \mathrm{m}), 7.26(1 \mathrm{H}, \mathrm{t}, \mathrm{Ar}-\mathrm{H}), 7.15$ $(1 \mathrm{H}, \mathrm{s}, \mathrm{NH}), 6.76(1 \mathrm{H}, \mathrm{d}, \operatorname{Ar}-\mathrm{H}), 6.69(1 \mathrm{H}, \mathrm{t}, \mathrm{Ar}-\mathrm{H}), 5.79(1 \mathrm{H}, \mathrm{s}, \mathrm{CH}) .{ }^{13} \mathrm{C} N M R(75 \mathrm{MHz}$, DMSO- $\left.d_{6}\right): \delta 163.98,148.13,141.13,133.87,133.46,129.23,128.78,127.85,117.76$, $115.42,114.94,66.25$.

2-(4-Nitrophenyl)-2,3-dihydroquinazolin-4(1H)-one 3b: ${ }^{1} \mathrm{H}$ NMR ((300 MHz, DMSO-d6, delta, ppm): $8.53(1 \mathrm{H}, \mathrm{s}, \mathrm{NHCO}), 8.25(2 \mathrm{H}, \mathrm{d}), 7.75(2 \mathrm{H}, \mathrm{d}), 7.26(1 \mathrm{H}, \mathrm{d}), 7.34(1 \mathrm{H}, \mathrm{s}$, $\mathrm{NH}), 7.27(1 \mathrm{H}, \mathrm{t}), 6.78(1 \mathrm{H}, \mathrm{d}), 6.69(1 \mathrm{H}, \mathrm{t}, \mathrm{Ar}-\mathrm{H}), 5.93(1 \mathrm{H}, \mathrm{s}, \mathrm{CH}) .{ }^{13} \mathrm{C} \mathrm{NMR}(75 \mathrm{MHz}$, DMSO- $\left.d_{6}\right): \delta 163.76,149.78,147.89,147.71,134.04,129.28,128.05,127.88,124.57$, $124.05,117.94,115.37,115.02,65.77$.

2-(4-Methyphenyl)-2,3-dihydroquinazolin-4(1H)-one 3c: ${ }^{1} \mathrm{H}$ NMR (300 MHz, DMSO-d6, delta, ppm): $8.23(1 \mathrm{H}, \mathrm{s}, \mathrm{NHCO}), 7.61(1 \mathrm{H}, \mathrm{d}, \mathrm{Ar}-\mathrm{H}), 7.37(2 \mathrm{H}, \mathrm{b}, \mathrm{Ar}-\mathrm{H}), 7.27-7.18(3 \mathrm{H}$, $\mathrm{m}), 7.05(1 \mathrm{H}, \mathrm{s}, \mathrm{NH}), 6.74(1 \mathrm{H}, \mathrm{d}, \mathrm{Ar}-\mathrm{H}), 6.67(1 \mathrm{H}, \mathrm{t}, \mathrm{Ar}-\mathrm{H}), 5.71(1 \mathrm{H}, \mathrm{s}, \mathrm{CH}), 2.30(3 \mathrm{H}$, $\left.\mathrm{s}, \mathrm{CH}_{3}\right) .{ }^{13} \mathrm{C}$ NMR $\left(75 \mathrm{MHz}\right.$, DMSO- $\left.d_{6}\right): \delta 164.10,148.38,139.13,138.87,133.18,133.72$, $129.27,127.80,127.26,117.53,115.47,114.87 .25,66.84,21.19$. 
2-Phenyl-2,3-dihydroquinazolin-4(1H)-one 3d: ${ }^{1} \mathrm{H}$ NMR(300 MHz, DMSO-d6, delta, ppm): $8.30(1 \mathrm{H}, \mathrm{s}, \mathrm{NHCO}), 7.64(1 \mathrm{H}, \mathrm{d}, \operatorname{Ar}-\mathrm{H}), 7.51(2 \mathrm{H}, \mathrm{d}), 7.40(3 \mathrm{H}, \mathrm{m}), 7.25(1 \mathrm{H}, \mathrm{t}, \mathrm{Ar}-\mathrm{H})$, $7.12(1 \mathrm{H}, \mathrm{s}, \mathrm{NH}), 6.76(1 \mathrm{H}, \mathrm{d}, \mathrm{Ar}-\mathrm{H}), 6.69(1 \mathrm{H}, \mathrm{t}, \mathrm{Ar}-\mathrm{H}), 5.77(1 \mathrm{H}, \mathrm{s}, \mathrm{CH}) .{ }^{13} \mathrm{C}$ NMR $(75$ $\mathrm{MHz}$, DMSO- $\left.d_{6}\right): \delta 164.08,148.35,142.10,133.79,128.93,128.80,127.83,127.34$, $117.59,115.43,114.88,67.05$.

2-(4-Methoxyphenyl)-2,3-dihydroquinazolin-4(1H)-one 3e: ${ }^{1} \mathrm{H} \mathrm{NMR}\left(300 \mathrm{MHz}, \mathrm{DMSO}-\mathrm{d}_{6}\right.$, delta, ppm): $8.21(1 \mathrm{H}, \mathrm{s}, \mathrm{NHCO}), 7.63(1 \mathrm{H}, \mathrm{d}, \mathrm{Ar}-\mathrm{H}), 7.43(2 \mathrm{H}, \mathrm{d}, \mathrm{Ar}-\mathrm{H}), 7.22(1 \mathrm{H}, \mathrm{t}, \mathrm{Ar}-$ $\mathrm{H}), 7.03(1 \mathrm{H}, \mathrm{s}, \mathrm{NH}), 6.94(2 \mathrm{H}, \mathrm{d}, \mathrm{Ar}-\mathrm{H}), 6.76(1 \mathrm{H}, \mathrm{d}, \mathrm{Ar}-\mathrm{H}), 6.67(1 \mathrm{H}, \mathrm{t}, \mathrm{Ar}-\mathrm{H}), 5.73(1 \mathrm{H}$, $\mathrm{s}, \mathrm{CH}), 3.75\left(3 \mathrm{H}, \mathrm{s}, \mathrm{OCH}_{3}\right) .{ }^{13} \mathrm{C}$ NMR $\left(75 \mathrm{MHz}, \mathrm{DMSO}-\mathrm{d}_{6}\right): \delta 164.23,159.92,148.51$, $133.91,133.71,128.71,127.84,117.58,115.48,114.90,114.10,66.84,55.63$.

2-(2,3-Dimethoxyphenyl)-2,3-dihydroquinazolin-4(1H)-one 3f: ${ }^{1} \mathrm{H}$ NMR(300 MHz, DMSO$\mathrm{d}_{6}$, delta, ppm): $8.05(1 \mathrm{H}, \mathrm{s}, \mathrm{NHCO}), 7.65(1 \mathrm{H}, \mathrm{d}, \mathrm{Ar}-\mathrm{H}), 7.27-7.22(1 \mathrm{H}, \mathrm{t}, \mathrm{Ar}-\mathrm{H}), 7.11-$ $7.03(3 \mathrm{H}, \mathrm{m}), 6.81(1 \mathrm{H}, \mathrm{s}, \mathrm{NH}), 6.78-6.67(2 \mathrm{H}, \mathrm{m}), 6.06(1 \mathrm{H}, \mathrm{s}, \mathrm{CH}), 3.83\left(3 \mathrm{H}, \mathrm{s}, \mathrm{OCH}_{3}\right)$, $3.81\left(3 \mathrm{H}, \mathrm{s}, \mathrm{OCH}_{3}\right) .{ }^{13} \mathrm{C} \mathrm{NMR}\left(75 \mathrm{MHz}, \mathrm{DMSO}-d_{6}\right): \delta 164.24,152.72,148.47,146.60$, $134.94,133.72,127.80,124.37,119.56,117.54,115.20,114.91,113.47,61.69,61.19$, 56.28 .

\section{RESULTS AND DISCUSSION}

To start up, the 2,3-dihydroquinazolin-4(1H)-one synthesis reaction has been chosen (Scheme 1) as a model in order to study the catalytic activity of heterogeneous catalysts MAP, DAP and TSP. The results obtained are summarized in Table 1.

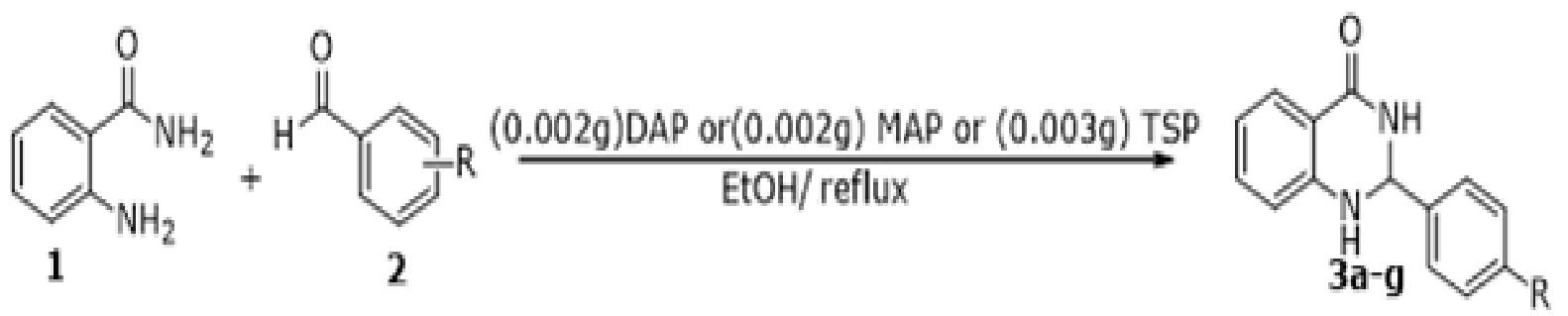

Scheme 1. Synthesis reaction of 2,3-dihydroquinazolin-4(1H)-one. 
Table 1. Yields and reaction times obtained without catalyst and using MAP, DAP and TSP catalysts in case of the 2,3-dihydroquinazolin-4(1H)-ones synthesis ${ }^{\text {a }}$.

\begin{tabular}{|c|c|c|c|}
\hline Entry & Catalyst & Time (min) & Yield (\%) \\
\hline 1 & - & 60 & trace \\
\hline 2 & MAP & 30 & 83 \\
\hline 3 & DAP & 40 & 80 \\
\hline 4 & TSP & 40 & 86 \\
\hline
\end{tabular}

Table 1 shows that in absence of the catalysts, the product $\mathbf{3 a}$ has been obtained as a trace within a reaction time of $60 \mathrm{~min}$. When we added MAP, DAP and TSP as catalysts, the yields were 83,80 and $86 \%$ respectively while the reaction times were shorter than the one obtained without a catalyst. Then, our work was concentrated on the improvement of the reaction yields by the determination the optimal conditions.

We consider at first the optimization of the reaction time of the synthesis of 2, 3dihydroquinazolin- $4(1 \mathrm{H})$-one, Figure 1 illustrated the reaction time concerning the conversion of 4-chlorobenzaldehyde to anthranylamide.

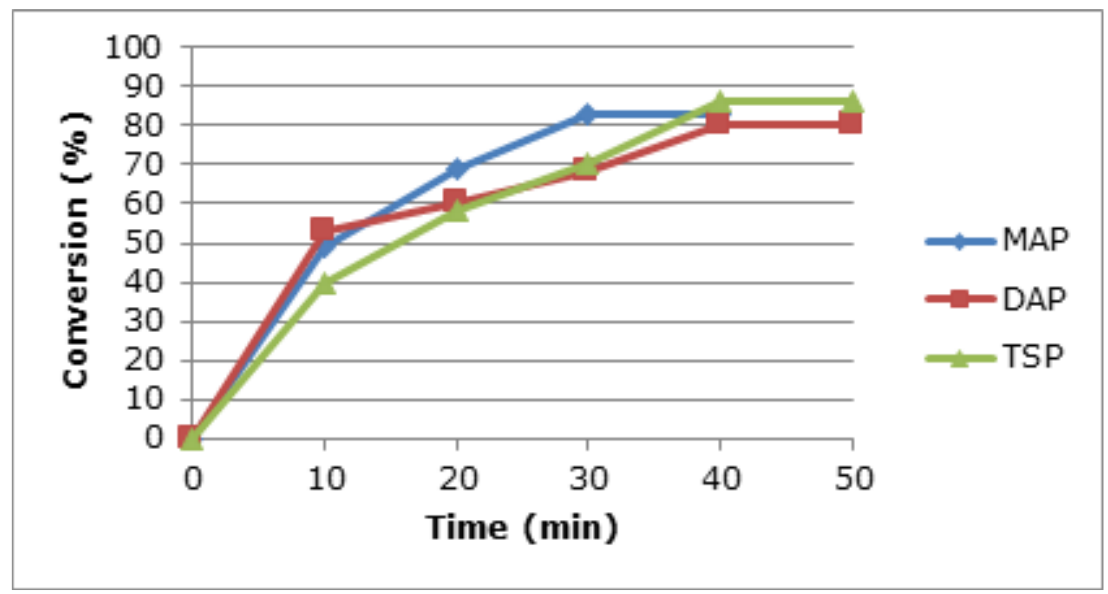

Figure 1. Reaction time optimization of 2,3-dihydroquinazolin-4(1H)-one synthesis.

From Figure 1, one can notice that the catalytic activity increases over time to reach a level representing the catalytic stability. The conversion rates obtained are respectively $83 \%$ for the catalyst MAP, $80 \%$ for the catalyst DAP and $86 \%$ for the TSP catalyst. Therefore, it can be concluded that the optimum reaction time is $30 \mathrm{~min}$ for the catalyst MAP and 40 min for catalysts DAP and TSP. 
Then, the effect of certain porous polar solvents such as ( $\mathrm{EtOH}, \mathrm{MeOH}, \mathrm{BuOH})$, polar aprotic $\left(\mathrm{CH}_{3} \mathrm{CN}, \mathrm{THF}\right)$ and apolar aprotic (chloroform) was studied, the results are grouped in Table 2 .

Table 2. Solvent effect on the synthesis of 2,3-dihydroquinazolin-4(1H)-one ${ }^{a}$.

\begin{tabular}{lcccccc}
\hline \multirow{2}{*}{ Entry } & Solvent & \multicolumn{3}{c}{ Time (min) } & \multicolumn{3}{c}{ Yield (\%) } \\
\cline { 3 - 7 } & & MAP & DAP & TSP & MAP & DAP \\
\hline 1 & EtOH & 30 & 40 & 40 & 83 & 80 \\
\hline 2 & MeOH & 30 & 40 & 40 & 81 & 80 \\
\hline 3 & n-Butanol & 30 & 40 & 40 & 78 & 76 \\
\hline 4 & Acetonitrile & 30 & 40 & 40 & 70 & 74 \\
\hline 5 & Chloroform & 30 & 40 & 40 & 67 & 70 \\
\hline 6 & THF & 30 & 40 & 40 & 62 & 64 \\
\hline a Reaction & conditions: & anthranylamide & $(1$ & mmol), \\
\hline \\
chlorobenzaldehyde (1
\end{tabular}

According to the obtained results, the reaction is carried out more easily in ethanol, due to its high dipole moment and high dielectric constant which allows the separation of the charges, thus facilitating the product 3a formation with yields by 83,80 and $86 \%$ for the three catalysts MAP, DAP, and TSP respectively.

The use of another solvent such as $\mathrm{CH}_{3} \mathrm{CN}$, chloroform, and THF gives the final product $\mathbf{3 a}$ with lower yields than those obtained in ethanol, this can be probably explained by their dipole moment and constant dielectric which are lower than those of ethanol, it can be deduced, that the ethanol has been chosen as the solvent for the reaction of 2, 3dihydroquinazolin-4(1H)-one.

Among the main parameters that control the cost of the reaction is the solvent volume used. For this reason, we envisage studying the influence of volume of the solvent on the reaction yield, this is carried out by varying the volume of the ethanol from 3 to $1 \mathrm{~mL}$ in case of the model reaction. The results are summarized in Table 3. 
Table 3. Solvent volume effect on the 2,3-dihydroquinazolin-4(1H)-one synthesis ${ }^{\text {a }}$.

\begin{tabular}{|c|c|c|c|c|c|c|}
\hline \multirow[t]{2}{*}{ Entry } & \multirow[t]{2}{*}{ Volume } & \multicolumn{2}{|c|}{ Time (min) } & \multicolumn{3}{|c|}{ Yield (\%) } \\
\hline & & MAP & DAP & TSP & MAP & DAP \\
\hline 1 & $1 \mathrm{~mL}$ & 30 & 40 & 40 & 85 & 83 \\
\hline 2 & $2 \mathrm{~mL}$ & 30 & 40 & 40 & 84 & 81 \\
\hline 3 & $3 \mathrm{~mL}$ & 30 & 40 & 40 & 83 & 80 \\
\hline
\end{tabular}

Table 3 shows that the best yield corresponds to $1 \mathrm{~mL}$ of ethanol, but when one increases the volume until $3 \mathrm{~mL}$ we observe a reduction of the yield of the reaction, this may be due to the deactivation of the interaction between the reactants and the catalyst by the formation of a layer on the surface of the catalyst. Thus, it can be concluded that the optimum volume for carrying out this reaction is $1 \mathrm{~mL}$.

In the next step, it is fundamental to determine the optimum catalyst mass, thus we studied the influence of the amounts of catalysts MAP, DAP, and TSP on the yield on the reaction, the mass of catalyst has been varied from 0.001 to $0.01 \mathrm{~g}$, the results are collected in Table 4.

Table 4. Catalyst amount optimization for the synthesis of 2,3-dihydroquinazolin-4(1H)one synthesis ${ }^{a}$.

\begin{tabular}{|c|c|c|c|c|c|c|c|c|}
\hline \multirow[t]{2}{*}{ Entry } & \multicolumn{3}{|c|}{ Amount of catalyst $(\mathrm{g} / \mathrm{mol} \%)$} & \multicolumn{3}{|c|}{ Time (min) } & \multicolumn{2}{|c|}{ Yield \% ${ }^{b}$} \\
\hline & MAP & DAP & TSP & MAP & DAP & TSP & MAP & DAP \\
\hline 1 & $0.001 / 0.8$ & $0.001 / 0.7$ & $0.001 / 0.4$ & 30 & 40 & 40 & 92 & 89 \\
\hline 2 & $0.002 / 1.7$ & $0.002 / 1.5$ & $0.002 / 0.8$ & 30 & 40 & 40 & 96 & 94 \\
\hline 3 & $0.003 / 2.6$ & $0.003 / 2.3$ & $0.003 / 1.2$ & 30 & 40 & 40 & 96 & 93 \\
\hline 4 & $0.004 / 3.3$ & $0.004 / 3.1$ & $0.004 / 1.7$ & 30 & 40 & 40 & 95 & 90 \\
\hline 5 & $0.005 / 3.5$ & $0.005 / 3.8$ & $0.005 / 2.2$ & 30 & 40 & 40 & 92 & 89 \\
\hline 6 & $0.006 / 5.2$ & $0.006 / 4.6$ & $0.006 / 2.6$ & 30 & 40 & 40 & 91 & 87 \\
\hline 7 & $0.007 / 6.1$ & $0.007 / 5.3$ & $0.007 / 2.9$ & 30 & 40 & 40 & 88 & 85 \\
\hline 8 & $0.008 / 6.9$ & $0.008 / 6.1$ & $0.008 / 3.4$ & 30 & 40 & 40 & 87 & 84 \\
\hline 9 & $0.009 / 7.8$ & $0.009 / 6.8$ & $0.009 / 3.9$ & 30 & 40 & 40 & 86 & 82 \\
\hline 10 & $0.01 / 8.5$ & $0.01 / 7.6$ & $0.01 / 4.3$ & 30 & 40 & 40 & 85 & 83 \\
\hline
\end{tabular}

aReaction conditions: Anthranylamide $(1 \mathrm{mmol}), 4$-chlorobenzaldehyde $(1 \mathrm{mmol})$, $\mathrm{EtOH}(1 \mathrm{~mL}), \mathrm{xg}$ of catalyst. ${ }^{\mathrm{b}}$ Isolated yields. 
The results presented in Table 4 show that the optimum masses of MAP, DAP and TSP catalysts were respectively $0.002 \mathrm{~g}(1.7 \mathrm{~mol} \%), 0.002 \mathrm{~g}(1.5 \mathrm{~mol} \%)$ and $0.003 \mathrm{~g}(1.2$ $\mathrm{mol} \%)$. Beyond these masses, the yields of the reaction decrease, this is explained by the dispersion of the reagents on the surface of the catalysts.

After having optimized reaction conditions, namely the reaction time, the solvent nature as well as its volume and the mass of the catalyst. It is fundamental to examine the evolution turnover number (TON) and turnover frequency (TOF) in function of the catalysts mass used, for the pilot reaction. Table 5 present the calculated values.

Table 5.TON and TOF values for MAP, DAP and TSP catalysts used in the synthesis of 2,3Dihydroquinazolin-4(1H)-One.

\begin{tabular}{|c|c|c|c|c|c|c|c|c|}
\hline \multirow{2}{*}{$\begin{array}{c}\text { Amount of } \\
\text { catalyst (g) }\end{array}$} & \multicolumn{3}{|c|}{ Time (h) } & \multicolumn{3}{c|}{ TON } & \multicolumn{2}{c|}{ TOF(h-1) } \\
\cline { 2 - 8 } & MAP & DAP & TSP & MAP & DAP & TSP & MAP & DAP \\
\hline 0.001 & $1 / 2$ & $2 / 3$ & $2 / 3$ & 116.27 & 131.57 & 232.55 & 232.54 & 199.34 \\
\hline 0.002 & $1 / 2$ & $2 / 3$ & $2 / 3$ & $\mathbf{5 8 . 8 2}$ & $\mathbf{6 6 . 6 6}$ & 117.64 & $\mathbf{1 1 7 . 6 4}$ & $\mathbf{1 0 1 . 0 0}$ \\
\hline 0.003 & $1 / 2$ & $2 / 3$ & $2 / 3$ & 38.46 & 43.47 & $\mathbf{8 3 . 3 3}$ & 77.28 & 65.86 \\
\hline 0.004 & $1 / 2$ & $2 / 3$ & $2 / 3$ & 29.41 & 32.25 & 58.82 & 58.82 & 48.86 \\
\hline 0.005 & $1 / 2$ & $2 / 3$ & $2 / 3$ & 28.57 & 26.31 & 45.45 & 57.14 & 39.86 \\
\hline 0.006 & $1 / 2$ & $2 / 3$ & $2 / 3$ & 19.23 & 21.73 & 38.46 & 38.46 & 32.92 \\
\hline 0.007 & $1 / 2$ & $2 / 3$ & $2 / 3$ & 16.39 & 18.86 & 34.48 & 32.78 & 28.57 \\
\hline 0.008 & $1 / 2$ & $2 / 3$ & $2 / 3$ & 14.49 & 16.39 & 29.41 & 28.98 & 24.83 \\
\hline 0.009 & $1 / 2$ & $2 / 3$ & $2 / 3$ & 12.82 & 14.70 & 25.64 & 25.64 & 22.27 \\
\hline 0.01 & $1 / 2$ & $2 / 3$ & $2 / 3$ & 11.62 & 13.15 & 23.25 & 23.24 & 19.92 \\
\hline
\end{tabular}

TON and TOF values in bold correspond to the amounts, $0.002 \mathrm{~g}$ for MAP and DAP and $0.003 \mathrm{~g}$ for TSP, that were used in this study.

The high values of TON and TOF were found for $0.001 \mathrm{~g}$ for the three catalysts. From the table above, it is clear that The TON and TOF increase when the mass of catalyst decrease. Their values are higher between 0.001 and $0.003 \mathrm{~g}$ of each catalyst. Such as it showed before and by considering the optimum reaction time, the best yields were obtained using $0.002 \mathrm{~g}$ for MAP and DAP and $0.003 \mathrm{~g}$ for TSP this led to the yield about $95 \%$ for the pilot reaction.

One of the most important characteristics of a catalyst is its activity which is linked to the evaluation of its stability and its capacity to be reused for several times without any loss of efficiency. The reusability of MAP, DAP, and TSP catalysts has been studied under the optimum reaction conditions determined above, after completion of the reaction, the 
catalyst was filtered and washed several times with ethanol and then dried, the results are presented in Figure 2.

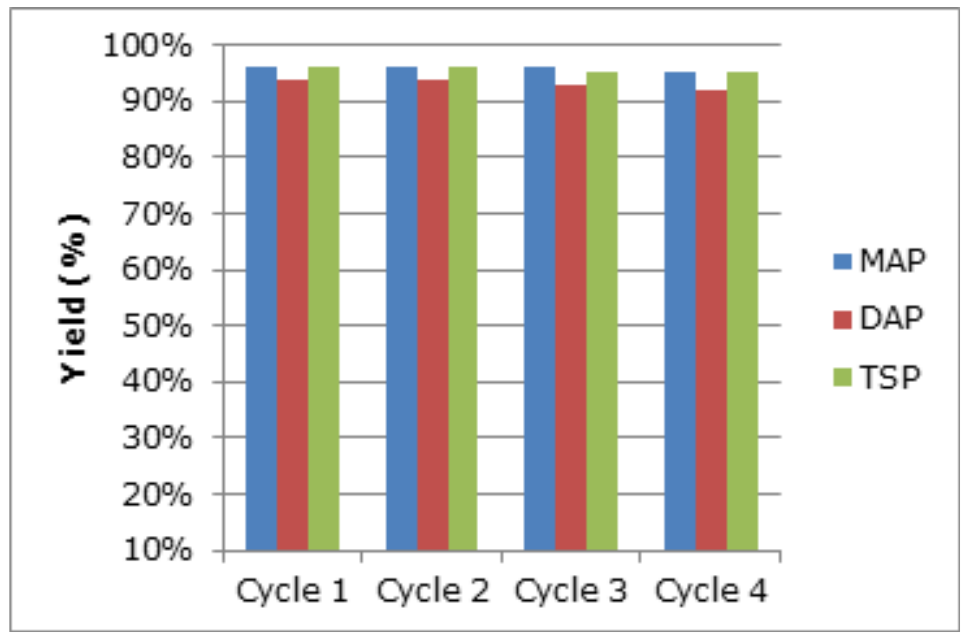

Figure 2. Recyclability of catalyst MAP, DAP and TSP.

According to Figure 2, it is observed that the yields remain unchanged as a function of the number of regeneration cycles; this suggests that there is no loss of catalytic activity, even after four times of reusability of the catalysts. Thus, one can deduce that the long term durability of these catalysts is excellent.

After optimizing the reaction conditions of 2, 3-dihydroquinazolin-4(1H)-one synthesis, this process was generalized for the derivatives of 2, 3-dihydroquinazolin-4(1H)-one synthesis, using various aromatic aldehydes substituted with anthranylamide (Scheme 1). The melting points were determined and showed a good agreement compared to those given in the literature, the results are presented in Table 6.

Table 6. Generalization to the synthesis of 2,3-dihydroquinazolin-4(1H)-one derivatives.

\begin{tabular}{|c|c|c|c|c|c|}
\hline \multirow[t]{2}{*}{ Compound no } & \multirow[t]{2}{*}{$\mathbf{R}$} & \multicolumn{3}{|c|}{ Yield (\%) / Time (min) } & \multirow{2}{*}{$\begin{array}{r}\text { Melting } \\
\text { point }\left({ }^{\circ} \mathrm{C}\right. \\
\text { Found }\end{array}$} \\
\hline & & MAP & DAP & TSP & \\
\hline $3 a$ & $4-\mathrm{Cl}$ & $96 / 30$ & $94 / 40$ & $96 / 40$ & 204-205 \\
\hline 3b & $4-\mathrm{NO}_{2}$ & $89 / 30$ & $91 / 35$ & $92 / 35$ & $199-200$ \\
\hline $3 c$ & $4-\mathrm{CH}_{3}$ & $92 / 27$ & $93 / 30$ & $95 / 32$ & $232-233$ \\
\hline 3d & $\mathrm{H}$ & $93 / 20$ & $90 / 28$ & $94 / 25$ & $219-220$ \\
\hline $3 e$ & $4-\mathrm{OCH}_{3}$ & $95 / 30$ & $96 / 40$ & $93 / 40$ & $192-193$ \\
\hline $3 f$ & $2,3-\mathrm{OCH}_{3}$ & $85 / 35$ & $81 / 40$ & $79 / 40$ & $220-221$ \\
\hline $\mathbf{3 g}$ & $4-\mathrm{N}\left(\mathrm{CH}_{3}\right)_{2}$ & $90 / 30$ & $89 / 40$ & $90 / 40$ & $227-228$ \\
\hline
\end{tabular}


The results show that whatever the grouping of the aldehyde electron donor $\left(\mathrm{Cl}, \mathrm{OH}, \mathrm{OCH}_{3}\right.$, $\left.\mathrm{CH}_{3}\right)$ or electron attractors $\left(\mathrm{NO}_{2}\right)$, the products are obtained with excellent yields in very short reaction times.

The proposed the catalytic mechanism for the condensation of an aromatic aldehyde and anthranylamide, using MAP catalyst, for the synthesis of 2,3-dihydroquinazolin-4 (1H)-one (Scheme 2).
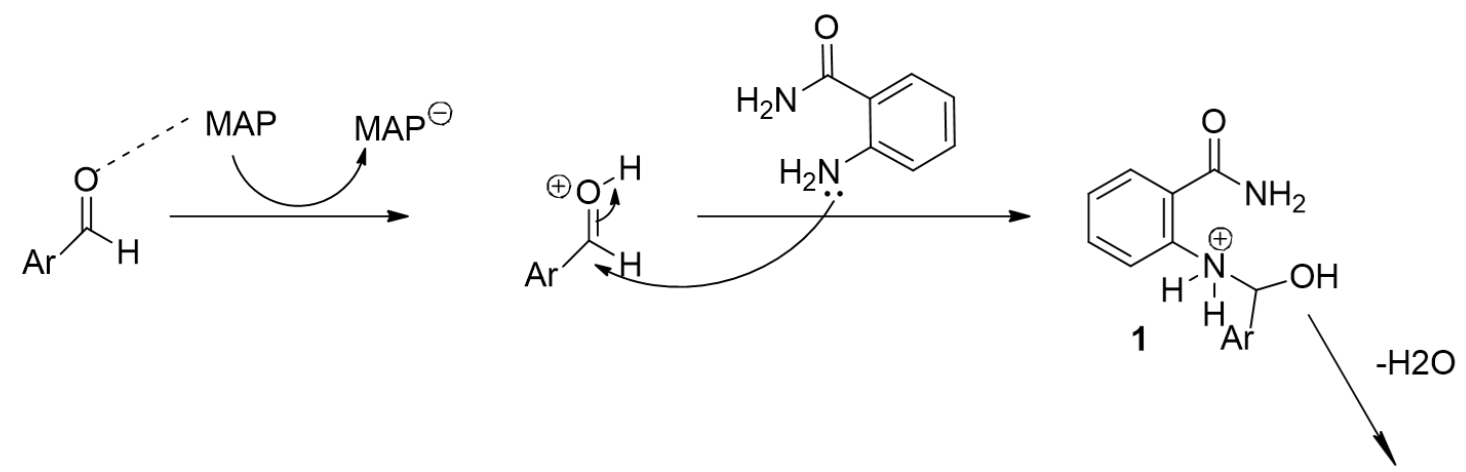<smiles>O=C1NC(Br)Nc2ccccc21</smiles>

3a

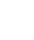

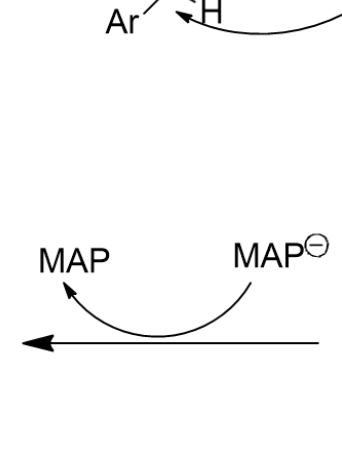

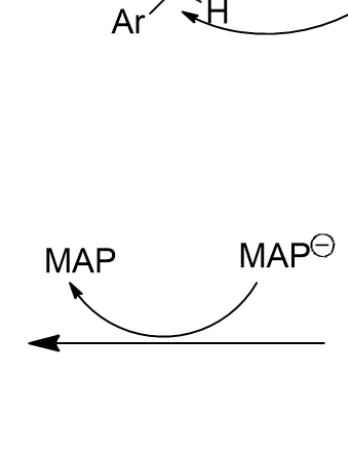

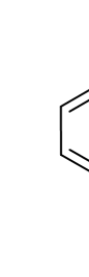<smiles>NC(=O)c1ccccc1N=CBr</smiles>

Scheme 2. A plausible mechanism for the formation of 2,3-dihydroquinazolin-4(1H)-one.

From this scheme, the probable mechanism for the synthesis of 2,3-dihydroquinazolin-4 $(1 \mathrm{H})$-one, first the protonation of the carbonyl group with MAP take place, subsequently the amino group of anthranylamide makes a nucleophilic attack on the activated carbonyl group, since the amino is more reactive than the amide, which allows the formation of an imine intermediate 1 , which then leads to the elimination of a molecule of water, followed by an intramolecular nucleophilic attack of the amide group on the imine carbon 2, finally deprotonation occurs for the formation of the desired product $3 a$, as shown in the Scheme 2 .

For the DAP and TSP, the catalytic mechanisms must be similar to the one given in Scheme 2 since the three catalysts act with the reagent by a proton exchange as they are potential donors of the proton. 
After determining the best-operating conditions for the synthesis of 2, 3-dihydroquinazolin$4(1 \mathrm{H})$-one, it would be interesting to compare the catalyst activities of MAP, DAP, and TSP used herein with those given in the literature. The results are summarized in Table 7.

Table 7. Efficiency comparison of various catalysts used in the condensation of anthranylamides and benzaldehyde condensation in various reaction conditions.

\begin{tabular}{ccccc}
\hline Entry & Catalyst & Reaction conditions & Time & Yield (\%) \\
\hline 1 & $\mathrm{MAP}$ & $\mathrm{EtOH} /$ reflux & $20 \mathrm{~min}$ & 93 \\
2 & $\mathrm{DAP}$ & $\mathrm{EtOH} /$ reflux & $28 \mathrm{~min}$ & 90 \\
3 & $\mathrm{TSP}$ & $\mathrm{EtOH} /$ reflux & $25 \mathrm{~min}$ & 94 \\
4 & $\mathrm{Al}^{3+}-\mathrm{ExIC}$ & $\mathrm{EtOH} / \mathrm{reflux}$ & $6 \mathrm{~h}$ & $95(34)$ \\
5 & $\mathrm{Sc}(\mathrm{OTf})_{3}$ & $\mathrm{CH}_{2} \mathrm{Cl} / 2 / \mathrm{RT}$ & $4 \mathrm{~h}$ & $94(35)$ \\
6 & $\mathrm{ZnCl}_{2}$ & $\mathrm{EtOH} / 80^{\circ} \mathrm{C}$ & $3 \mathrm{~h}$ & $59(36)$ \\
7 & $\mathrm{LaCl}_{3}$ & $\mathrm{EtOH} / 80^{\circ} \mathrm{C}$ & $1,5 \mathrm{~h}$ & $79(36)$ \\
8 & $\mathrm{PEG}-400$ & $100-110^{\circ} \mathrm{C}$ & $10 \mathrm{~h}$ & $85(24)$ \\
9 & {$\left[\mathrm{MIMC}_{4} \mathrm{SO}_{3} \mathrm{H}\right]\left[\mathrm{HSO}_{4}\right]$} & $110^{\circ} \mathrm{C}$ & 1,5 & $69(37)$ \\
10 & $\mathrm{CAN}$ & $\mathrm{H}_{2} \mathrm{O} / 60^{\circ} \mathrm{C}$ & $2 \mathrm{~h}$ & $92(38)$ \\
11 & $\mathrm{Trifluoroethanol}_{12}$ & $\mathrm{Reflux}$ & $1,5 \mathrm{~h}$ & $90(39)$ \\
12 & Oxalic Acid & $\mathrm{EtOH}: \mathrm{H}_{2} \mathrm{O} / 80^{\circ} \mathrm{C}$ & $45 \mathrm{~min}$ & $88(40)$ \\
\hline
\end{tabular}

For 11 and 12 entries, homogenous catalysts were used.

From Table 7, one can deduce that the catalysts MAP, DAP and TSP possess an interesting catalytic activity and provide short times and excellent yields of the 2, 3-dihydroquinazolin$4(1 \mathrm{H})$-one synthesis compared to catalysts $\mathrm{Al}^{3+}$-ExIC, Sc(OTf) $3, \mathrm{ZnCl}_{2}, \mathrm{LaCl}_{3}, \mathrm{PEG}-400$, $\left[\mathrm{MIMC}_{4} \mathrm{SO}_{3} \mathrm{H}\right]\left[\mathrm{HSO}_{4}\right]$, trifluoroethanol and oxalic acid that give low yields and along reaction times.

\section{CONCLUSION}

To sum up, an environmentally friendly method, for the synthesis of derivatives 2,3dihydroquinazolin- $4(1 \mathrm{H})$-one by condensation of anthranylamide with aromatic aldehyde using phosphate fertilizers (MAP, DAP, and TSP) as heterogeneous catalysts, was developed. The operational conditions were optimized namely the nature and volume of solvent as well as the amount of catalyst. The products were obtained with excellent yields in short reaction times and the catalysts can be used for at least four times without any loss in its catalytic activity. These results are better than the ones given in previous works. Moreover, the catalysts are natural and cheap and their use is harmful to the environment. 
Therefore, this method can be used for the synthesis of a wide series of heterocyclic compounds in the way to protect the environment against chemical pollution.

\section{REFERENCES}

1. Birch HL, Buckley GM, Davies N, Dyke HJ, Frost EJ, Gilbert PJ, et al. Novel 7-methoxy-6-oxazol5-yl-2,3-dihydro-1H-quinazolin-4-ones as IMPDH inhibitors. Bioorg Med Chem Lett. 2005;15(23):5335-9.

2. Cohen E, Klarberg B, Vaughan JR. QUINAZOLINONE SULFONAMIDES AS DIURETIC AGENTS. J Am Chem Soc. 1959;81(20):5508-9.

3. Yadav MR, Shirude ST, Parmar A, Balaraman R, Giridhar R. Synthesis and anti-inflammatory activity of 2,3-diaryl-4(3H)-quinazolinones. ChemHeterocycl Compd. 2006; 42(8):1038-1045.

4. Carlo M, Anna B, Isabella S, Maria S, Andrea R, Rosella F, et al. Synthesis and evaluation as NOP ligands of some spiro[piperidine-4, $2^{\prime}\left(1^{\prime} \mathrm{H}\right)$-quinazolin]-4' $\left(3^{\prime} \mathrm{H}\right)$-ones 3 and spiro[piperidine4,5'(6’H)-[1,2,4]triazolo[1,5-c]quinazolines]. Chem Pharm Bull (Tokyo). 2006;54(5):611-622.

5. Bonola G, Da Re P, Magistretti MJ, Massarani E, Setnikar I. 1-Aminoacyl-2,3-dihydro-4(1H)quinazolinone derivatives with choleretic and antifibrillatory activity. J Med Chem.1968;11(6):11369.

6. Hess HJ, Cronin TH, Scriabine A. Antihypertensive 2-amino-4(3H)-quinazolinones. J Med Chem. $1968 ; 11(1): 130-6$.

7. Levin JI, Chan PS, Bailey T, Katocs AS, Venkatesan AM. The synthesis of 2,3-dihydro-4(1H)quinazolinone angiotensin II receptor antagonists. Bioorg Med Chem Lett. 1994;4(9):1141-6.

8. Okumura K, Oine T, Yamada Y, Hayashi G, Nakama M. 4-Oxo-1,2,3,4-tetrahydroquinazolines. I. Syntheses and pharmacological properties of 2-methyl-3-aryl-4-oxo-1,2,3,4-tetrahydroquinazolines and their 1-acyl derivatives. J Med Chem. 1968;11(2):348-52.

9. Alagarsamy V, Solomon VR, Murugan M. Synthesis and pharmacological investigation of novel 4benzyl-1-substituted-4H-[1,2,4]triazolo[4,3-a]quinazolin-5-ones as new class of $\mathrm{H} 1$-antihistaminic agents. Bioorg Med Chem. 2007;15(12):4009-15.

10. Chinigo GM, Paige M, Grindrod S, Hamel E, Dakshanamurthy S, Chruszcz M, Minor W, Brown M. Asymmetric Synthesis of 2,3-Dihydro-2-arylquinazolin-4-ones: Methodology and Application to a Potent Fluorescent Tubulin Inhibitor with Anticancer Activity. J Med Chem. 2008;51(15):4620-31.

11. White DC, Greenwood TD, Downey AL, Bloomquist JR, Wolfe JF. Synthesis and anticonvulsant evaluation of some new 2-substituted-3-arylpyrido[2,3-d]pyrimidinones. Bioorg Med Chem. 2004;12(21):5711-7.

12. Sharma M, Chauhan K, Shivahare R, Vishwakarma P, Suthar MK, Sharma A, et al. Discovery of a New Class of Natural Product-Inspired Quinazolinone Hybrid as Potent Antileishmanial agents. J Med Chem. 2013;56(11):4374-92.

13. Baghbanzadeh M, Salehi P, Dabiri M, Kozehgary G. Water-Accelerated Synthesis of Novel Bis2,3-dihydroquinazolin-4(1 H )-one Derivatives. Synthesis. 2006;(2):344-8.

14. Karimi-Jaberi Z, Arjmandi R. Acetic acid-promoted, efficient, one-pot synthesis of 2,3dihydroquinazolin-4(1H)-ones. MonatshefteFürChem - Chem Mon. 2011;142(6):631-5.

15. Niknam K, Mohammadizadeh MR, Mirzaee S. Silica-bonded S-sulfonic Acid as a Recyclable Catalyst for Synthesis of 2,3-Dihydroquinazolin-4(1H)-ones. Chin J Chem. 2011;29(7):1417-22. 
16. Yoo CL, Fettinger JC, Kurth MJ. Stannous Chloride in Alcohol: A One-Pot Conversion of 2-Nitro$\mathrm{N}$-arylbenzamides to 2,3-Dihydro-1 H -quinazoline-4-ones. J Org Chem. 2005;70(17):6941-3.

17. Surpur MP, Singh PR, Patil SB, Samant SD. Expeditious One-Pot and Solvent-Free Synthesis of Dihydroquinazolin-4(1H)-ones in the Presence of Microwaves. Synth Commun. 2007;37(12):196570.

18. Shaterian HR, Oveisi AR, Honarmand M. Synthesis of 2,3-Dihydroquinazoline-4(1 H )-ones. Synth Commun. 2010;40(8):1231-42.

19. Kassaee MZ, Rostamizadeh S, Shadjou N, Motamedi E, Esmaeelzadeh M. An efficient one-pot solvent-free synthesis of 2,3-dihydroquinazoline-4(1H)-ones via Al/Al2O3 nanoparticles. J Heterocycl Chem. 2010;47(6):1421-4.

20. Tarannum S, Ahmed N, Siddiqui ZN. LaCl3/nano-SiO2: A novel nanocatalyst for efficient synthesis of functionalized 2,3-dihydroquinazolinones. CatalCommun. 2015;66:60-6.

21. Ghorbani-Choghamarani A, Azadi G. Synthesis, characterization, and application of Fe 304 SA-PPCA as a novel nanomagnetic reusable catalyst for the efficient synthesis of 2,3dihydroquinazolin-4(1H)-ones and polyhydroquinolines. RSC Adv. 2015;5(13):9752-8.

22. Wu J, Du X, Ma J, Zhang Y, Shi Q, Luo L, Song B, Yang S, Hu D. Preparation of 2,3dihydroquinazolin- $4(1 \mathrm{H})$-one derivatives in aqueous media with $\beta$-cyclodextrin-SO3H as a recyclable catalyst. Green Chem. 2014;16(6):3210-3217.

23. Abdollahi-Alibeik M, Shabani E. Nanocrystalline sulfated zirconia as an efficient solid acid catalyst for the synthesis of 2,3-dihydroquinazolin-4(1H)-ones. J Iran Chem Soc. 2014;11(2):3519.

24. Yerram P, Chowrasia R, Seeka S, Tangenda SJ. Polyethylene glycol (PEG-400) as a medium for novel and efficient synthesis of 2-phenyl-2,3-dihydroquinazolin-4(1H)-one derivatives. Eur J Chem. $2013 ; 4(4): 462-6$.

25. Chen J, Su W, Wu H, Liu M, Jin C. Eco-friendly synthesis of 2,3-dihydroquinazolin-4(1H)-ones in ionic liquids or ionic liquid-water without additional catalyst. Green Chem. 2007;9(9):972.

26. Bahammou I, Esaady A, Boukhris S, Ghailane R, Habbadi N, Hassikou A, et al. Direct use of mineral fertilizers MAP, DAP, and TSP as heterogeneous catalysts in organic reactions. Mediterr J Chem. 2016;5(6):615.

27. Sibous S, Boukhris S, Ghailane R, Habbadi N, Hassikou A, Souizi A. easy synthesis of 3,4dihydropyrimidin -2-(1h)-ones using phosphate fertilizers MAP, DAP and TSP as efficient catalysts. J Turk Chem. Soc Sect A Chem. 2017;4(2):477-488.

28. Sibous S, Ghailane T, Houda S, Ghailane R, Boukhris S, Souizi A. Green and efficient method for the synthesis of 1,5-benzodiazipines using phosphate fertilizers as catalysts under free solvent. Mediterr J Chem. 2017;6(3):53.

29. Wang M, Zhang TT, Song ZG. Eco-friendly synthesis of 2-substituted-2,3-dihydro-4(1H)quinazolinones in water. Chin Chem Lett. 2011;22(4):427-30.

30. Shaterian HR, Oveisi AR. PPA-SiO 2 as a Heterogeneous Catalyst for Efficient Synthesis of 2Substituted-1,2,3,4-tetrahydro-4-quinazolinones under Solvent-free Conditions. Chin J Chem. $2009 ; 27(12): 2418-22$.

31. Benzekri Z, Serrar H, Boukhris S, Souizi A. FeCl3/Egg shell: An Effective Catalytic System for the Synthesis of 2,3-Dihydroquinazolin-4(1H)-ones at Room Temperature. J Turk Chem. Soc. Sect A Chem. 2017;4(3):775-786. 
32. Chen J, Wu D, He F, Liu M, Wu H, Ding J, et al. Gallium(III) triflate-catalyzed one-pot selective synthesis of 2,3-dihydroquinazolin-4(1H)-ones and quinazolin-4(3H)-ones. Tetrahedron Lett. $2008 ; 49(23): 3814-8$.

33. Rostami A, Tavakoli A. Sulfamic acid as a reusable and green catalyst for efficient and simple synthesis of 2-substituted-2,3-dihydroquinazolin-4(1H)-ones in water or methanol. Chin Chem Lett. $2011 ; 22(11): 1317-20$.

34. Kancherla $M$, Badathala V. Aluminium exchanged Indian clay as an efficient reusable green catalyst for synthesis of 2, 3-dihydroquinazolin-4(1H)-one derivatives. J Porous Mater. 2017;24(5):1187-96.

35. Vasudhevan S, Joel Karunakaran R. Synthesis, Characterisation of 2,3-Dihydroquinazolinone Derivatives and their Antimicrobial Studies. Int J ChemTech Res. 2013;5(6):2844-53.

36. Shang Y-H, Fan L-Y, Li X-X, Liu M-X. Y(OTf)3-catalyzed heterocyclic formation via aerobic oxygenation: An approach to dihydroquinazolinones and quinazolinones. Chin Chem Lett. $2015 ; 26(11): 1355-8$.

37. Yassaghi G, Davoodnia A, Allameh S, Zare-Bidaki A, Tavakoli-Hoseini N. Preparation, Characterization and First Application of Aerosil Silica Supported Acidic Ionic Liquid as a Reusable Heterogeneous Catalyst for the Synthesis of 2,3-Dihydroquinazolin-4(1H)-ones. Bull Korean Chem Soc. $2012 ; 33(8): 2724-30$.

38. M W, J. J G, Z. G S, L W. Cerium(IV) ammonium nitrate catalyzed green synthesis of 2substituted 2,3-dihydro- quinazolin-4(1H)-ones using a grinding technique. ChemHeterocycl Compd. 2011;47(7):851-855.

39. Qiao RZ, Xu BL, Wang YH. A facile synthesis of 2-substituted-2,3-dihydro-4(1H)-quinazolinones in 2,2,2-trifluoroethanol. Chin Chem Lett. 2007;18(6):656-8.

40. Karhale $S$, Survase D, Bhat R, Ubale $P$, Helavi V. A practical and green protocol for the synthesis of 2,3-dihydroquinazolin-4(1H)-ones using oxalic acid as organocatalyst. Res ChemIntermed. 2017;43(7):3915-24. 